\title{
A histopathological study of granulomatous lesions
}

\author{
Akanksha Kushwah ${ }^{1}$, Narendra Bhattarai ${ }^{2}$, Ajay Koirala ${ }^{3}$ \\ ${ }^{1}$ Institute of Medicine, Tribhuwan University teaching hospital, Kathmandu, Nepal \\ ${ }^{2}$ Department of Pathology, Grande International Hospital Pvt. Ltd, Kathmandu, Nepal \\ ${ }^{3}$ Reading Hospital, Tower health system, West reading, PA USA
}

\section{Keywords: \\ Epithelioid; \\ Fungus; \\ Granuloma; \\ Histiocyte; \\ Tuberculosis;}

\begin{abstract}
Background: Granulomas are the commonest lesions that the pathologists come across in routine practice. Granulomatous inflammation is a special type of chronic inflammation that is a manifestation of many infective, toxic, allergic, autoimmune and neoplastic diseases and also conditions of unknown etiology. The aim of this study is to analyze different granulomatous lesions and to find the frequency and etiology of all granulomatous lesions.
\end{abstract}

Materials and Methods: The study included a total of 218 granulomatous lesions, received over a period of one year from July 2013 to June 2014 in the department of pathology, TUTH. Special stains like ZiehlNeelsen, PAS and Wade- Fite- Faraco were done whenever required.

Results: Granulomatous lesion accounted for 3\% of all biopsies. The median age of the patients was 29 years and the majority of the patients were in the age group of 20-29 years with no sex predilection. Majority of granulomas were seen in lymph nodes $(32.1 \%)$, followed by skin and subcutis $(29.4 \%)$, and bones and joints (11\%). Tuberculosis was the most common cause of granuloma with $143(65.6 \%)$ cases, followed by leprosy, foreign body and fungal infection. The most common type of granuloma was epithelioid (87.2\%), followed by epithelioid with suppuration, histiocytic, foreign body and mixed inflammatory.

Conclusion: The granulomatous lesion is common in third decade of life with no sex predominance. The commonest site is lymph node with tuberculosis being the most common cause followed by leprosy. The epithelioid type was the most common type of granuloma.

\section{Correspondence:}

Dr. Akansha Kushwah, MD

1670 Penn Avenue, apt b1, Wyomissing 19610 Pennsylvania, USA

ORCID ID: 0000-0001-5459-3321

Email: akanksha.kushwah22@gmail.com

Received : April 1 $1^{\text {st }} 2018$; Accepted : July 15 $5^{\text {th }} 2018$; Published : September $1^{\text {st }} 2018$

Citation: Kushwah A, Bhattarai N, Koirala A. A histopathological study of granulomatous lesions. J Pathol Nep 2018;8:1341-5. DOI: 10.3126/jpn.v8i2.20863

Copyright: This is an open-access article distributed under the terms of the Creative Commons Attribution 4.0 International License, which permits unrestricted use, distribution, and reproduction in any medium, provided the original author and source are credited.

\section{INTRODUCTION}

Granulomatous inflammation is a distinctive pattern of chronic inflammation that is encountered in a limited number of infectious and non-infectious conditions. ${ }^{1} \mathrm{~A}$ knowledge of the basic pathophysiology of this distinctive tissue reaction is therefore of fundamental importance in the understanding of many disease processes. ${ }^{2}$ Causes of granuloma include bacterial, metal-induced, fungal, viral, chlamydial, helminthic, foreign body and unknown cause. ${ }^{3}$ Granulomas are classified as follow: epithelioid, histiocytic, foreign body, necrobiotic, palisading and mixed inflammatory. ${ }^{4}$ Some epithelioid granulomas are necrotizing, while others show suppuration. 
Good clinical history, a close histological examination and a clinicopathological correlation is essential in making a final diagnosis. However in a minority of the cases, it will not be possible to make a definitive diagnosis, even with all the clinical information being available. In a small percentage of cases, no definitive diagnosis can be given, other than that of granulomatous inflammation. ${ }^{5}$

A rational histological diagnostic approach to granulomatous inflammation is also not present without its problems. Firstly, there is a diversity of macrophage morphologies. Secondly, the tissue reaction is a very individual process and, in particular, the status of the host's immune system is vital in how they react to the offending antigens. ${ }^{6}$

Special stains, culture for organisms, and molecular techniques may also be required to reach a diagnosis. By combining all the available information, one should be able to arrive at a reasonable differential diagnosis on which to proceed. ${ }^{5}$ This study was done to review and analyze all the cases of granulomatous lesions over one year period.

\section{MATERIAL AND METHODS}

This prospective descriptive study was carried out over a period of one year (2013/04/14 to 2014/04/13) with a sample size of 218 cases at the Department of Pathology, Institute of Medicine, Tribhuvan University Teaching Hospital, Kathmandu, Nepal. Approval of the study protocol by the Institutional Review Board of Institute of Medicine was obtained. All the granulomatous lesions on tissue biopsy sent for histopathological examination were included in the study. Detailed clinical data was obtained and noted in a structured proforma. This was to obtain information on age, sex, religion, site and distribution of lesion, duration of disease, presence of systemic illness, immunosuppressed status and whether prior FNAC was done or not.

The specimen received was fixed in $10 \%$ formalin for at least 24 hours and then subjected to histopathological processing and examination. The tissues were placed in tissue teks and processed in the histokinette after processing, the sections were embedded in paraffin and blocks were made. 5 micrometer sections were cut from the blocks and put into albuminized slides. The sections were then stained with hematoxylin and eosin stain and microscopic examination was done. The slides were reviewed by pathologist and diagnosis was made.

\section{RESULTS}

A total of 7294 histopathological specimens were received in the Department of Pathology. Out of which 218 cases $(0.3 \%)$ were granulomatous lesions. The median age of the patient with granulomatous lesion was 29 years with a range of 3-80 years (fig. 1). The majority of the patients were in the age range of 21-30 years. There was slight to no male predominance with male to female ratio of 1.04:1. Majority of the granulomas were seen in lymph node (32\%) followed by skin and subcutis (29\%), and bones and joints (11\%). Table 1 Other sites were respiratory tract, gastrointestinal tract, urinary system, omentum and others. Tuberculosis was the most common cause with 143 (66\%) cases, followed by Leprosy $22(10 \%)$ cases (table 2$)$. Other causes included foreign body reaction, fungal infections, sarcoidosis, erythema induratum, parasites, tumors, chalazion, crohn's disease, de Quervain's thyroiditis and BCG instillation. In 9 (4\%) cases, histomorphology, special stains and other laboratory parameters and clinicoradiological findings could not establish the cause of granulomatous inflammation, so they were just labelled as granulomatous lesions. FNA reports were available in 41 cases. There was concordance between FNAC diagnosis and Histopathological diagnosis in 25/41 (61\%) cases while discordance was found in 16/41 (39\%) cases.

In $97.9 \%$ cases of tuberculosis, the granuloma was epithelioid type. Fungal infection showed epithelioid granuloma with suppuration in $77.8 \%$ cases. Histiocytic granulomas were seen in tuberculosis, erythema induratum, granuloma annulare, leprosy and foreign body. Parasitic infection showed epithelioid, mixed inflammatory and palisading granulomas. (fig.2)

\section{DISCUSSION}

Granulomas are the commonest lesions that the pathologists come across in routine practice. In order to treat these lesions, definitive diagnosis by the demonstration of the aetiological agent is essential, which will bear an impact on the patient management and outcome. ${ }^{7}$ Fully developed granulomas with sheets of epithelioid histiocytes and giant cells are easily recognized, but more subtle lesions containing a few epithelioid histiocytes still qualify as granulomatous. It is difficult to present a completely satisfactory classification of the granulomatous reaction. Many conditions classified as granulomatous lesions may show only non-specific changes in the early evolution of the inflammatory process and in a late or resolving stage show fibrosis and non-specific changes without granulomas ${ }^{8}$

In the present study, we had a spectrum of patients with granulomatous lesions ranging from 3-80 years of age. Mean age of the patient was 29 years. Maximum frequency $(30.3 \%)$ was found in the age group 21-30 years, followed by $11-20$ years constituting $18.8 \%$. Similar results were found in other studies by Permi HS et $\mathrm{al}^{9}$ and Pawale $\mathrm{J}$ et $\mathrm{al}^{7}$, however unlike these studies there was no significant male predominance in the present study.

The commonest site was lymph node (32\%) followed by skin and subcutis (29\%), bones and joints (11\%), respiratory 


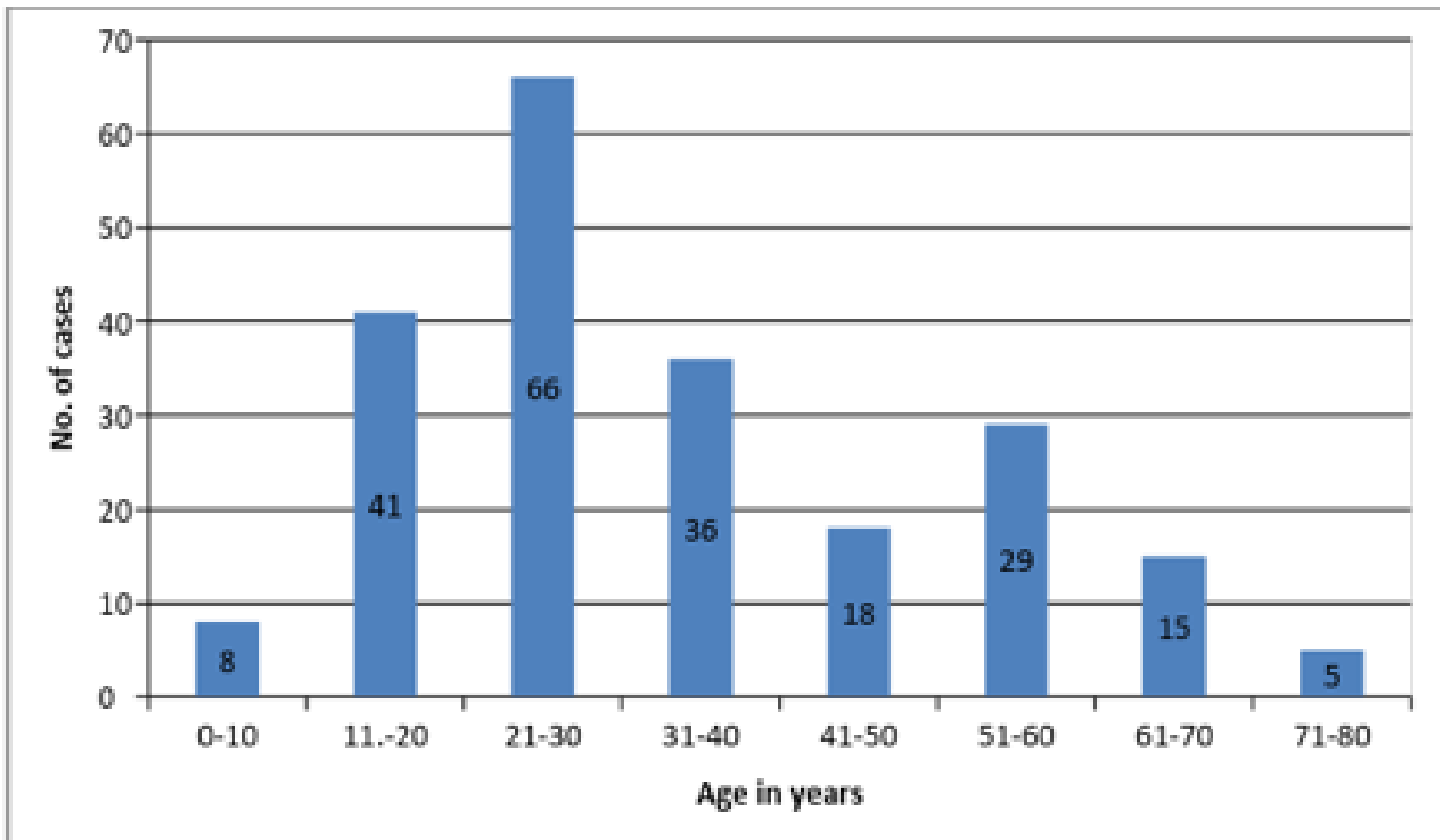

Figure 1: Age distribution of the patient

Table 1: Site wise distribution of Granulomas

\begin{tabular}{l|c|c}
\hline \multicolumn{1}{c}{ Site of Grabulomas } & Frequency & Percentage \\
\hline Lymph nodes & 70 & 32.1 \\
\hline Skin and subcutis & 64 & 29.4 \\
\hline Bones and Joints & 24 & 11.0 \\
\hline Respiratory tract & 17 & 7.8 \\
\hline Gastrointestinal tract & 12 & 5.5 \\
\hline Urinary system & 7 & 3.2 \\
\hline Omentum & 4 & 1.8 \\
\hline Hepatobiliary system & 4 & 1.8 \\
\hline Female genital tract & 3 & 1.4 \\
\hline Male genital system & 3 & 1.4 \\
\hline Thyroid & 2 & 0.9 \\
\hline Eye and ocular adnexae & 2 & 0.9 \\
\hline Breast & 2 & 0.9 \\
\hline Pericardium & 2 & 0.9 \\
\hline Salivary gland & 1 & 0.5 \\
\hline Brain & 1 & 0.5 \\
\hline Total & $\mathbf{2 1 8}$ & $\mathbf{1 0 0}$ \\
\hline
\end{tabular}

system, gastrointestinal tract, urinary system, omentum, female genital tract, male genital system, thyroid, eye and ocular adnexa, breast, pericardium, tonsils, salivary glands and brain. In a study by Permi HS et $\mathrm{al}^{9}$ the most common site of granulomatous lesion was skin and subcutis.

The most common cause of granuloma was tuberculosis followed by leprosy, foreign body granuloma and fungal in present study which is similar to other studies by Permi HS et $\mathrm{al}^{9}$ and Pawale $\mathrm{J}$ et al. ${ }^{7}$ Tuberculosis is much common in our population in spite of the active immunization programme through BCG vaccination. With emergence of anti-tuberculosis drug-resistant strains and AIDS epidemic, there has been a worldwide rise of tuberculosis in the recent years more so ever in poverty-struck areas of the world due to poor nutrition, poverty, non-availability of diagnostic aids and treatment, overcrowding and ignorance about the disease. Tuberculosis can involve any organ or tissue of the body including skin. Tuberculosis mostly affects young adults, in their most productive years. However, all age groups are at risk.

Nepal is a high-burden country for tuberculosis. About $45 \%$ of the total population is infected with TB and an estimated 20,000 new infectious cases of TB are reported each year. The estimated annual incidence rate for all types of TB disease is 187 per 100,000 populations. The annual incidence of new smear-positive TB cases is 83.5 per 100,000 populations. Disease patterns of tuberculosis have changed, with a higher incidence of disseminated and extrapulmonary disease now found. Extrapulmonary sites of infection commonly include lymph nodes, pleura, and osteoarticular areas, although any organ can be involved.10

Out of a total of 143 cases of tuberculosis 59 (41.3\%) cases were seen in lymph node followed by 24 (16.8\%) cases in bones and joints and 19 (13.3\%) cases in skin and subcutis. This was comparable to a study by Sreeramareddy CT et al in Nepal in which common sites for EPTB were lymph nodes $(42.6 \%)$ and peritoneum and/or intestines (14.8\%). ${ }^{11}$ 


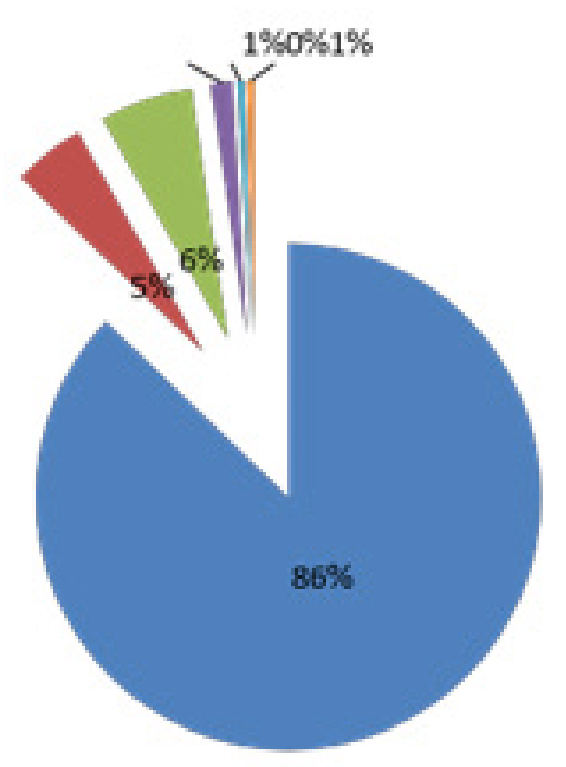

Epithelioid

Epithelioid with suppuration Histiocytic Foreign Body Mixed Inflammatory Palisading

Figure 2: Types of Granulomas

\section{Table 2: Etiology of Granulomas}

\begin{tabular}{lcc}
\hline \multicolumn{1}{c}{ Causes of Granulomas } & Frequency & Percentage \\
\hline Tuberculosis & 143 & 65.6 \\
\hline Leprosy & 22 & 10.1 \\
\hline Foreign body & 9 & 4.1 \\
\hline Fungal & 9 & 4.1 \\
\hline Sarcoidosis & 8 & 3.7 \\
\hline Erythema induratum & 4 & 1.8 \\
\hline Parasites & 3 & 1.4 \\
\hline Tumors & 3 & 1.4 \\
\hline Granuloma annulare & 2 & 0.9 \\
\hline Chalazion & 2 & 0.9 \\
\hline de Quervain's thyroiditis & 2 & 0.9 \\
\hline Crohn's Disease & 1 & 0.5 \\
\hline BCG instillation & 1 & 0.5 \\
\hline Unknown & 9 & 4.1 \\
\hline Total & $\mathbf{2 1 8}$ & $\mathbf{1 0 0}$ \\
\hline
\end{tabular}

In the present study, leprosy (22 cases, $34.4 \%$ ) constituted majority of the cases of granulomatous skin lesions. Tuberculoid leprosy (10 cases) predominated followed by Borderline tuberculoid ( 8 cases). Other cases were Erythema nodosum leprosum, Lepra reaction type 1, lepromatous leprosy and mid borderline (1 case each). In one study done by Gautam K et al12 leprosy constituted majority of granulomatous skin lesion similar to our study however, borderline tuberculoid predominated followed by indeterminate leprosy.
The present study showed female predominance of granulomatous lesions of the skin. But this result was not in accordance with Gautam K et $\mathrm{al}^{4}$ and Dhar $\mathrm{S}$ et $\mathrm{al}^{12}$ in which male predominance was seen. In a study by Zafar MNU et $\mathrm{al}^{13}$, females were more susceptible to develop granulomatous lesions of the skin (71/123).

Fungal infection of human is divided into the superficial mycoses and deep mycoses. Fungal infection was detected in $9(4.1 \%)$ cases, 2 of them showed epithelioid granuloma and 7 showed epithelioid granuloma with suppuration including 1 case with fungal element suggestive of sporotrichosis. Fungus was not identified in H\&E stained sections and special stain like PAS was needed to identify the fungus. PAS stain was done in 6 cases and was negative in 5 cases. In such cases histopathology can give only a clue to the referring dermatologist that he is dealing with a granulomatous lesion consistent with fungal infection. Patients were advised for culture, which is a definitive tool for confirmation of fungus and its species. This result was not comparable to other studies by Permi HS et al and Adhikari RC et al who found aspergillosis as the most common fungal infection in their studies.,

\section{CONCLUSION}

Even after highly effective anti-tubercular treatment, tuberculosis still remains the leading cause of granulomatous lesions. Most of the cases occurred between age 20s-30s with no sex predominance. Lymph node remains the most affected area of the body. FNAC is still a good diagnostic tool in evaluation of granulomatous lesion. 


\section{Conflict of interest: None}

\section{REFERENCES}

1. Permi HS, Shetty JK, Shetty PK et al. A Histopathological study of granulomatous inflammation. Nitte University Journal of health science 2012;2: 15-9.

2. Adams DO. The granulomatous inflammatory response. Am J Pathol 1976;84: 164-87. Crossref

3. Adhikari RC, Shrestha KB, Sayami G. Granulomatous inflammation: A histopathological study. J Pathol Nep 2013;3: 464-8. Crossref

4. Dhar S. Histopathological features of granulomatous skin diseases, analysis of 22 skin biopsies. Indian J Dermatol 2002;47:8890.

5. Pawale J, Purank R, Kulkarni MH. A histopathological study of granulomatous inflammations with an attempt to find the aetiology. $\mathrm{J}$ Clin Diagn Res 2011;5:301-6.

6. Blessing K. Cutaneous granulomatous inflammation. Current Diagnostic Pathology 2005;11:219-35. Crossref
7. National tuberculosis centre Annual report of national tuberculosis control progrmme. Ministry of Health, Kathmandu, Nepal 2015/2016. (Cited on 2nd March 2018) Crossref

8. Golden MP, Vikram HR. Extrapulmonary tuberculosis: an overview. Am FAM Physician 2005;72:1761-8. Crossref

9. Sreeramareddy CT, Panduru KV, Verma SC, Joshi HS, Bates MN. Comparison of pulmonary and extrapulmonary tuberculosis in Nepal- a hospital-based retrospective study. BMC infectious diseases 2008;8:8. Crossref

10. Gautam K, Pai RR, Bhat S. Granulomatous lesions of the skin. J Pathol Nep 2011;1:81-6. Crossref

11. Manonukul J, Wanitphakdeedecha R, Wisuthsarewong W, Thirapote P. Histopathologic aid to diagnosis of sarcoidosis: report of 8 cases. J Med Assoc Thai 2006;89:864-71. Crossref

12. Mohan H, Bal A, Dhami GP. Non-infectious granulomatous dermatitis: a clinicopathological study. J Cutan Pathol 2006;33:76771. Crossref

13. Zafar MNU, Sadiq S, Memon MA. Morphological study of different granulomatous lesions of the skin. Journal of Pakistan association of dermatologists 2008;18:21-8. 